\title{
Real-time Maximum Power Point Tracking Method for Stand-alone PV Array System under Partially Shaded Conditions
}

\author{
Yu-Chi Wu ${ }^{\text {a,* }}$ and Jhih-Huang Lin $^{\mathrm{b}}$ \\ Department of Electrical Engineering, National United University, \#2 Line-Da, Miao-Li, Taiwan \\ a ycwu@nu.edu.tw, b224988@yahoo.com.tw \\ *corresponding author
}

Keywords: Stand-alone solar system, partial shading maximum power point tracking method, realtime simulator, electrical characteristics.

\begin{abstract}
This paper studies the maximum power point tracking (MPPT) methods under partially shaded conditions for a stand-alone PV array system. The rules for judging partially shaded conditions are presented and integrated into four MPPT methods. These methods are tested in realtime simulation environment, and their advantages and disadvantages are further analyzed. Matlab/Simulink/SimPowerSystems are used with RT-Lab for building the real-time simulation models and the MPPT controller for partially shaded conditions. Based on the simulation results, the MPPT methods integrated with judging rules for partially shaded conditions can track the maximum power point better than those without judging rules, elevating the usage efficiency of PV arrays.
\end{abstract}

\section{Introduction}

The emphasis of the solar energy applications and the efficiency enhancement of solar cells result in decreasing their price and installation threshold [1]-[2]. World Energy Council (WEC) predicts that the contribution of all green energy to global energy supply would reach $21 \%$ by 2020 [3], making the demands for solar power significantly important.

Since the I-V curve for a PV array is non-linear, and its maximum power point changes with insolation and environmental temperature, the maximum power point tracking controller (MPPT controller) to convert solar energy with the maximum efficiency is therefore essential for the PV array. Nevertheless, large-scale solar power systems require larger coverage area and are often partially shaded by clouds, buildings, or trees. The P-V curve of solar cells therefore becomes bimodal and poly-modal. When improper maximum power point tracking controllers are used, the overall output power would be reduced. For this reason, to develop a maximum power point tracking controller suitable for partially shaded conditions is necessary.

Adding judging rules for partially shaded conditions to the MPPT methods could enhance the efficiency of the solar PV array system. In this paper, the improvement in the mis-judgment on the maximum power point tracking is proposed for PV array system under partial shading condition.

\section{Research Methodology}

In general, MPPT methods without taking partially shaded conditions into account could not correctly track the global maximum power point. The judging rules for partially shaded conditions proposed by Young-Hyok Ji et al. [4] are added to four MPPT methods for testing their effectiveness. Matlab/Simulink/SimPowerSystems are applied with RT-Lab in this study to construct MPPT controllers under partially shaded conditions for a stand-alone solar system. The architecture of this test system is shown in Figure 1, where the output voltage of the PV array controlled by the MPPT controller is connected to a buck-boost DC converter, and a $12 \mathrm{~V}$ battery is connected to the output of the DC converter to supply a load. The specifications of the PV array are shown in Table 1 [5]. The IV and PV curves of a single cell in the PV array with different partial 
shading areas (\%) are shown in Figures 2(a) and 2(b), respectively. The global and local maximum output power of the PV array under different partial shading conditions are shown in Table 2.

Table 1 Specifications of Kyocera 48W solar PV array [5]

\begin{tabular}{|c|c|}
\hline $\mathrm{P}_{\max }$ & $48 \mathrm{~W}$ \\
\hline $\mathrm{V}_{\mathrm{pmax}}$ & $17.9 \mathrm{~V}$ \\
\hline $\mathrm{I}_{\mathrm{pmax}}$ & $2.69 \mathrm{~A}$ \\
\hline $\mathrm{V}_{\mathrm{oc}}$ & $21.7 \mathrm{~V}$ \\
\hline $\mathrm{I}_{\mathrm{sc}}$ & $3 \mathrm{~A}$ \\
\hline
\end{tabular}

Table 2 Output power of PV under partially shaded conditions

\begin{tabular}{|c|c|c|c|c|c|}
\hline \multicolumn{6}{|c|}{$\begin{array}{l}\text { PV Array (three-cell parallel connection) under partially } \\
\text { shaded conditions }\end{array}$} \\
\hline & \multicolumn{4}{|c|}{ Global MPP } & Local MPP \\
\hline PV Array & \multicolumn{4}{|c|}{ Partially shaded area of PV } & \\
\hline Partially shaded & $20 \%$ & $40 \%$ & $60 \%$ & $80 \%$ & \\
\hline Outp & $40 \mathrm{~W}$ & $37.2 \mathrm{~W}$ & $35.6 \mathrm{~W}$ & $33.3 \mathrm{~W}$ & $32 \mathrm{~W}$ \\
\hline
\end{tabular}

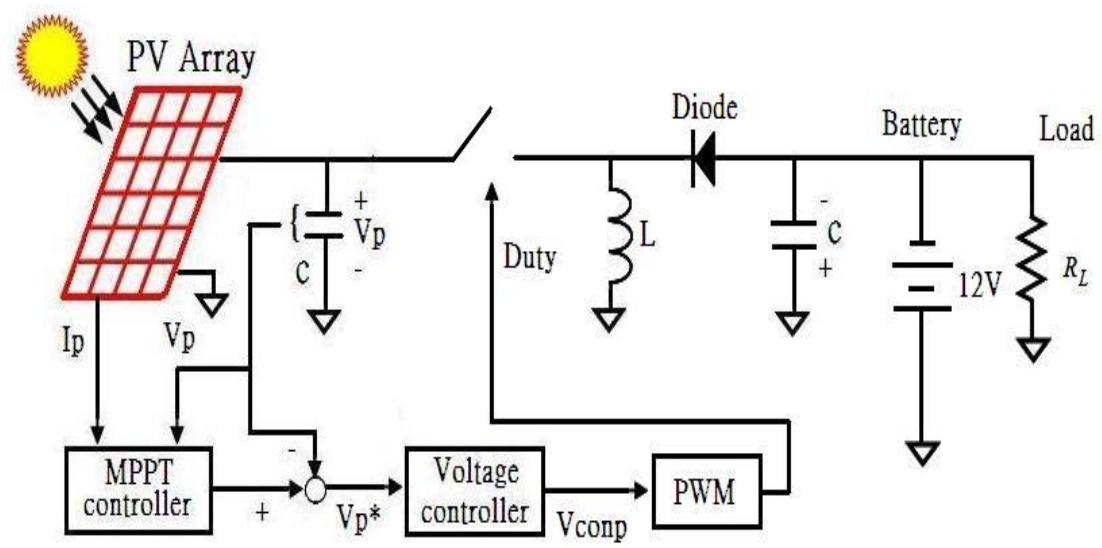

Figure 1 System architecture

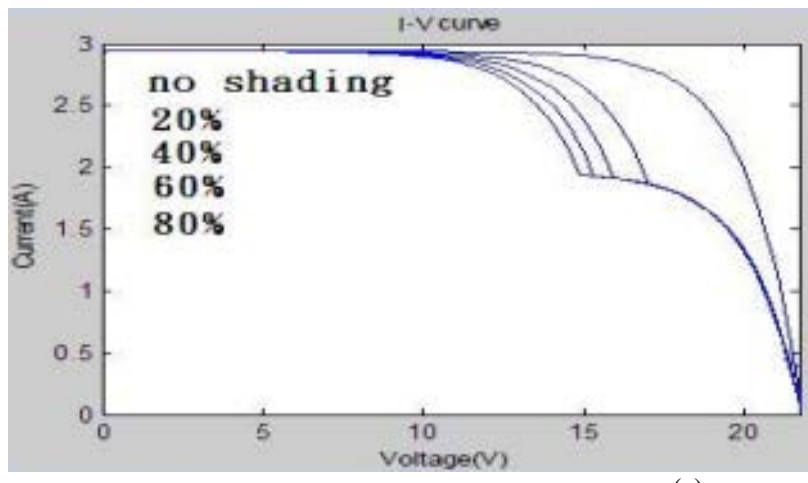

(a)

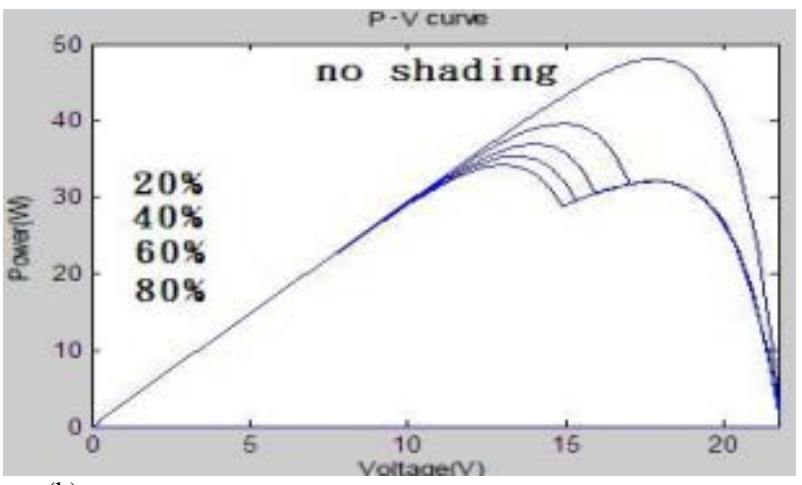

(b)

Figure 2 A single cell (PV1) in the solar PV array under different partially shaded areas (\%)

When the solar PV array system is partially shaded, an improper MPPT controller would affect the output efficiency of solar cells. Point A in Figure 3 shows the maximum power point without being partially shaded; one or several local maximum power points (Point B in Figure 3) or a global maximum power point (Point $\mathrm{C}$ in Figure 3) would appear on the P-V curve when being partially shaded. The use of a MPPT controller without adding the judging rules for partially shaded conditions could track the local maximum power point (Point B in Figure 3) so that the maximum usage of PV system cannot fully be developed. In this case, the judging rules for partially shaded conditions need to be added to the conventional MPPT methods.

The process of adding judging rules for partially shaded conditions to the maximum power tracking methods is shown in Figure 4. The green diagonal line in Figure 4 is formed by the origin point $(0,0)$ and the point $\left(V_{\mathrm{oc}}, \mathrm{I}_{\mathrm{sc}}\right)$. The current $\mathrm{I}_{\mathrm{p}}$ under partially shaded conditions is multiplied by the slope of this green line for a new operating voltage, $V_{c}$ in Figure 4 , which makes an order to retrack the global maximum power point, Point D in Figure 4. 


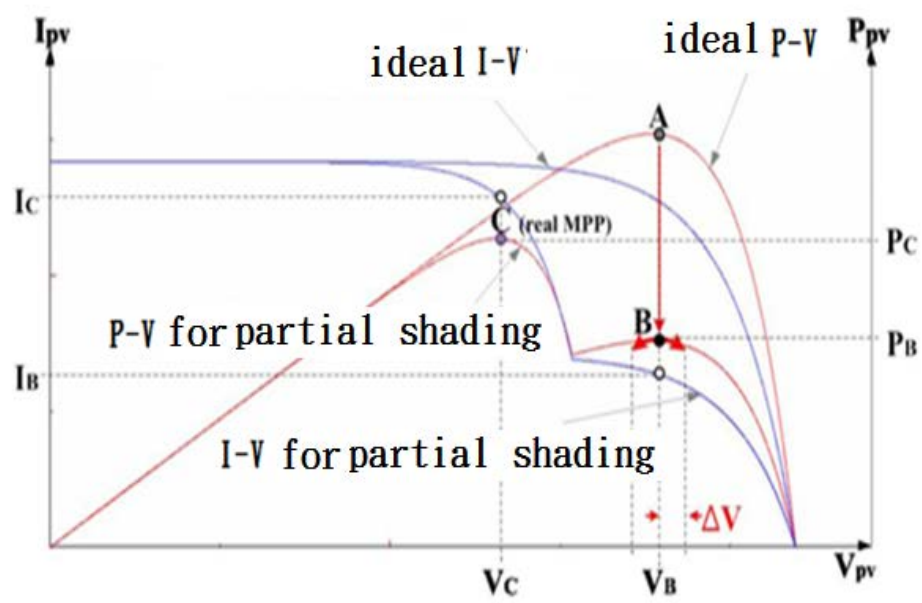

Figure $3 \mathrm{I}-\mathrm{V}$ and $\mathrm{P}-\mathrm{V}$ curves without/with partially shaded conditions

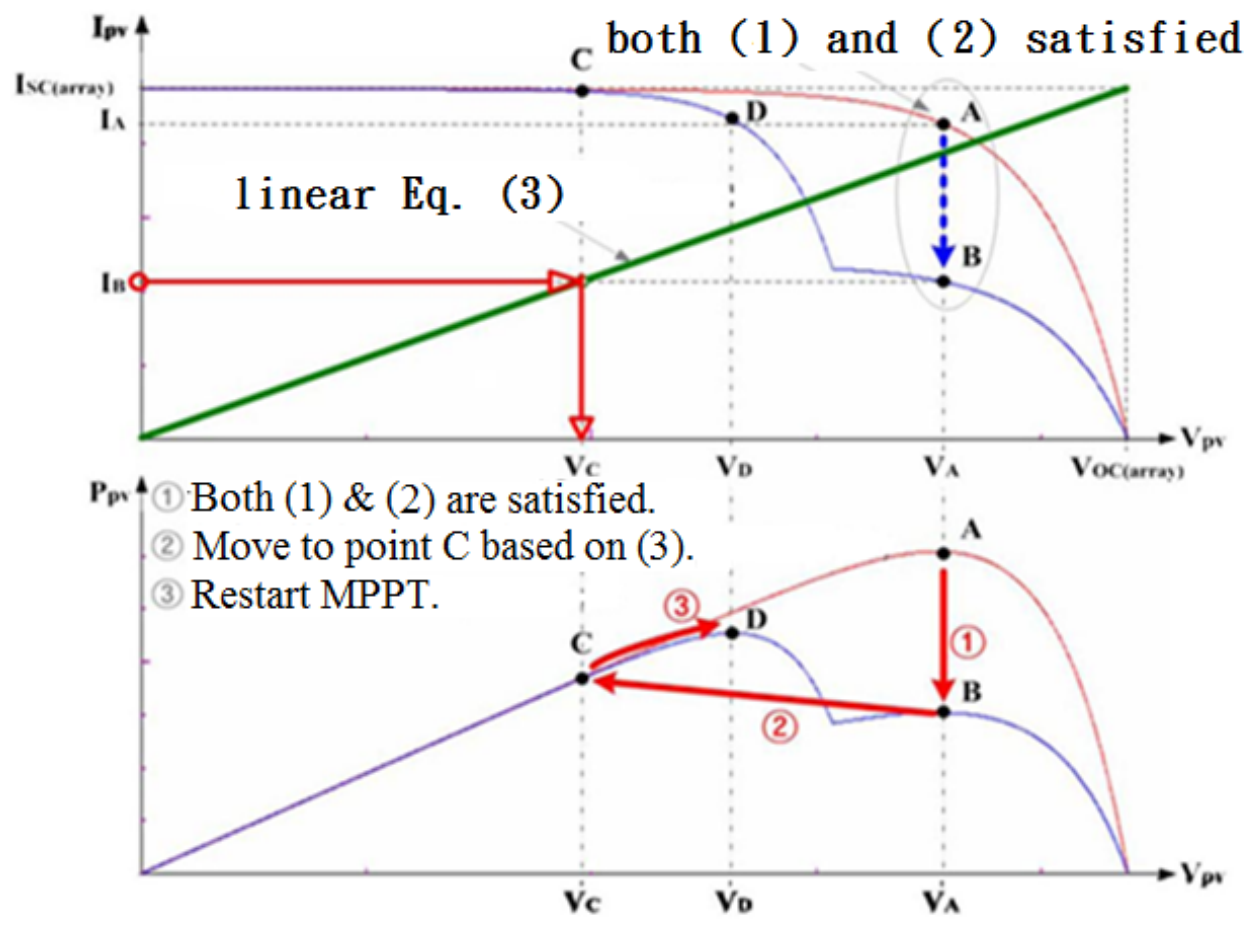

Figure 4 Working principle of the MPPT

$$
\begin{aligned}
& \Delta \mathrm{V}_{\mathrm{P}}=\mathrm{V}_{\mathrm{P}}[\mathrm{n}]-\mathrm{V}_{\mathrm{P}}[\mathrm{n}-1]<\Delta \mathrm{V}_{\mathrm{SET}} \\
& \frac{\Delta \mathrm{I}_{\mathrm{P}}}{\mathrm{I}_{\mathrm{P}}[\mathrm{n}-1]}=\left|\frac{\mathrm{I}_{\mathrm{P}}[\mathrm{n}]-\mathrm{I}_{\mathrm{P}}[\mathrm{n}-1]}{\mathrm{I}_{\mathrm{P}}[\mathrm{n}-1]}\right|<\Delta \mathrm{I}_{\mathrm{SET}} \approx \frac{\mathrm{I}_{\mathrm{P}}[\mathrm{n}-1]}{\mathrm{N}_{\mathrm{PM}}} \\
& V_{P}^{*}=\frac{N_{S} \times V_{O C}}{N_{P} \times I_{S C}} \times I_{P}[n]
\end{aligned}
$$

\section{Results}

The real-time simulation is performed based on RT-Lab using MATLAB/Simulink/ SimPowerSystems. The simulation tests are operated under the conditions: (1) standard insolation without partial shading and (2) dynamic partial shading.

Simulation 1: The total simulation time is $5 \mathrm{sec}$, and the load impedance is $5 \Omega$. Figure 5 shows 
the simulation results of four conventional MPPT methods (incremental conductance method [6], 4th order moving average filter [7], three-point weighting [8], three-point weighting with onemiddle-point tracking [8]) for the solar PV array without being partially shaded. Table 3 lists the performance data of four MPPT methods.

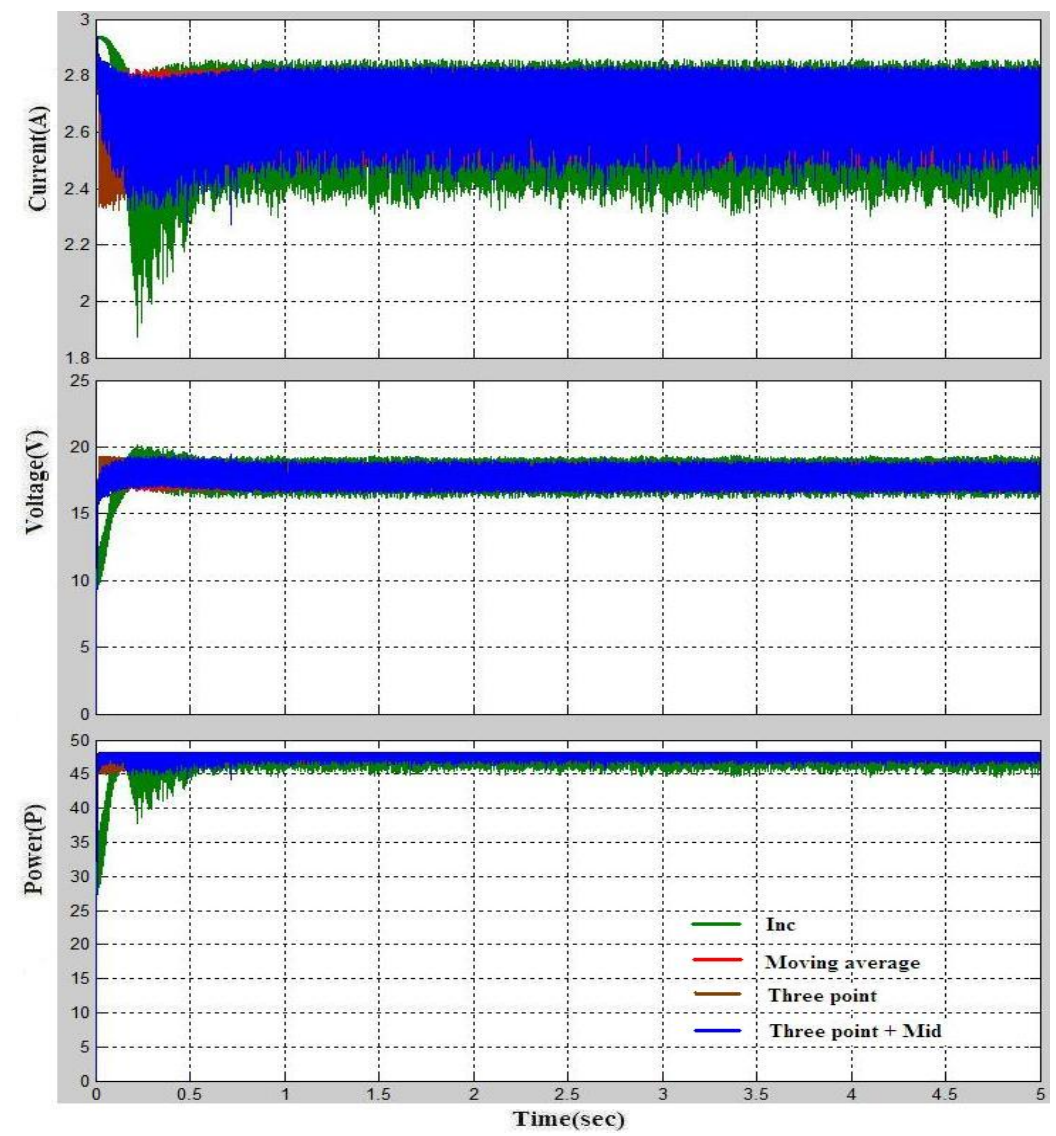

Figure 5 The maximum power tracking result under no partial shading condition

Table 3 Performance data of the four maximum power point tracking methods

\begin{tabular}{|c|c|c|c|c|}
\hline MPPT & $\begin{array}{c}\text { Incremental } \\
\text { conductance method }\end{array}$ & $\begin{array}{c}\text { 4th order moving } \\
\text { average filter }\end{array}$ & $\begin{array}{c}\text { three-point } \\
\text { weighting }\end{array}$ & $\begin{array}{c}\text { Three-point weighting with } \\
\text { one-middle-point tracking }\end{array}$ \\
\hline Tracking speed (s) & 0.1 & 0.015 & 0.015 & 0.0149 \\
\hline Oscillation loss (w) & 2.8 & 1.0 & 1.3 & 1.2 \\
\hline
\end{tabular}

Simulation 2: The total simulation time is 10sec. The solar cell PV1 is partially shaded at 2 4sec with shaded area $20 \%$ and $6 \sim 8$ sec with shaded area $40 \%$, and the load impedance is $5 \Omega$. The four MPPT methods without adding the judging rules for partial shading conditions only track the local maximum power (as Point B in Figure 3). The local maximum power appears only 32W. Figure 6 shows the corresponding output current, voltage, and power waveform of the PV array. As the judging rules for partial shading conditions are not added under partial shading conditions, the overall PV output efficiency is decreased. After adding the judging rules for partially shaded conditions to the four MPPT methods, the four MPPT methods now track the global maximum power point (as Point $C$ in Figure 3). Figure 7 shows the solar PV array output. Table 4 shows the comparison of the target value and the actual value of the PV array system tracked with the four MPPT methods under distinct dynamic partially shaded conditions. The actual values of the four MPPT methods are tracked to about the same point.

\section{Conclusions}

Adding the judging rules for partially shaded conditions to the four MPPT methods under 
partially shaded conditions is able to successfully and effectively re-track the global maximum value from the local one. The incremental conductance method appears worse performance on tracking speed and oscillation loss than the other three MPPT methods. Among the four MPPT methods, three-point weighting with one-middle-point tracking presents better tracking speed, oscillation loss, and tracking accuracy than the rest three, either with or without partially shaded conditions.

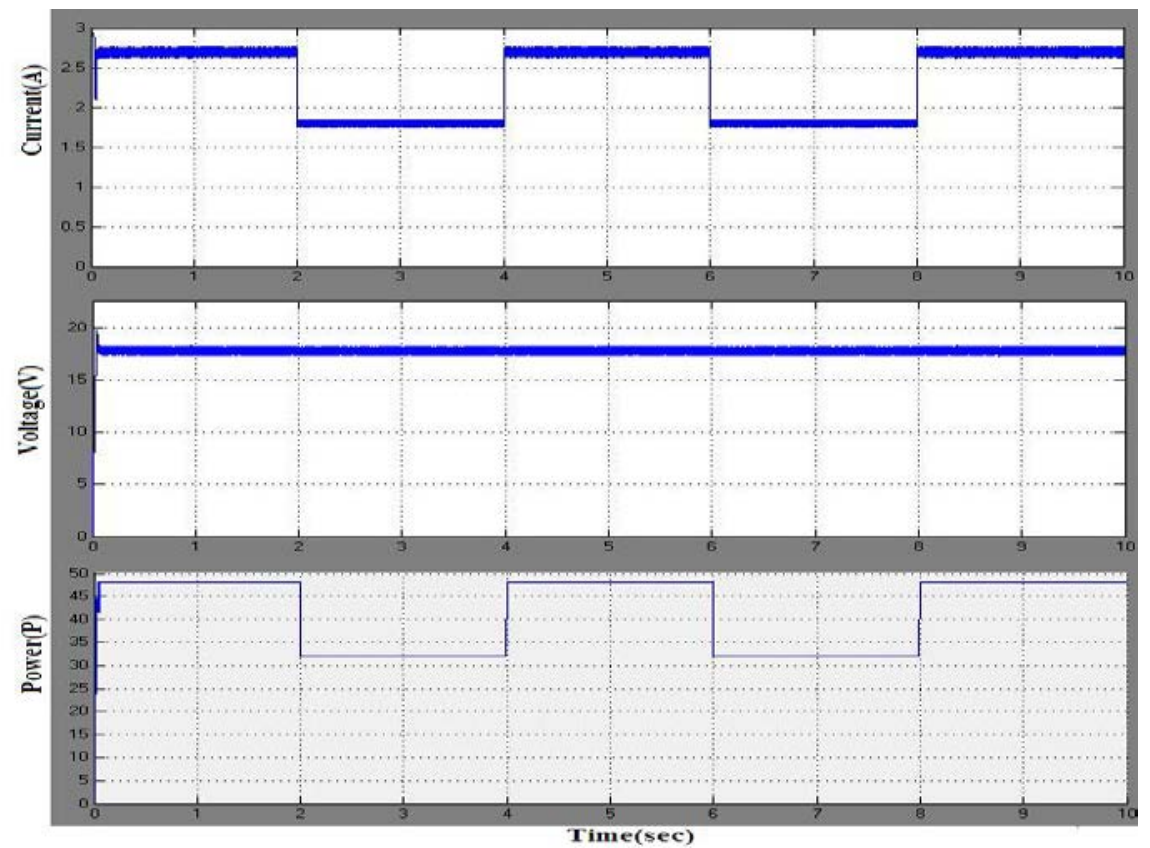

Figure 6 The solar PV array output without adding the judging rules for partially shaded conditions

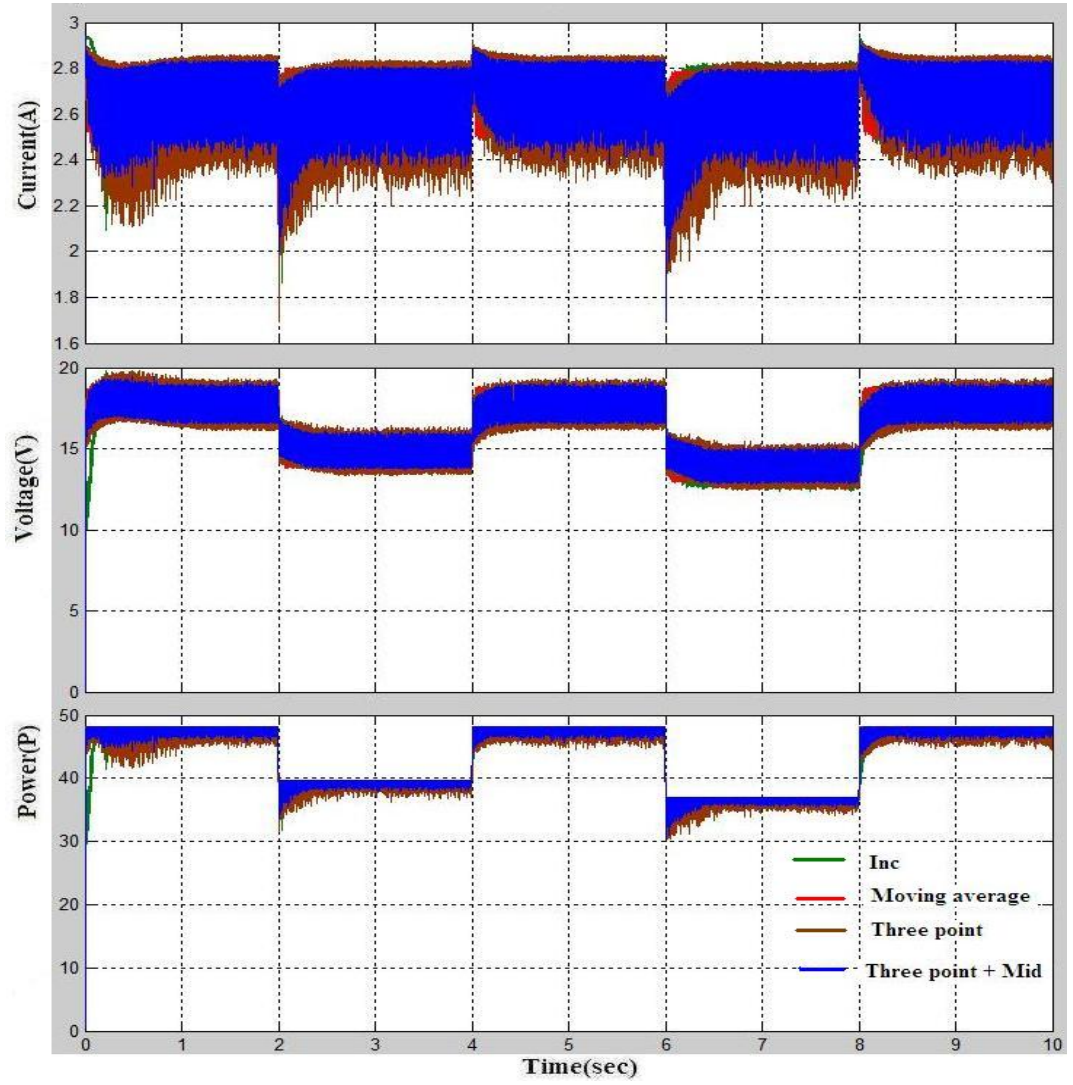

Figure 7 The solar PV array output after adding the judging rules for partially shaded conditions 
Table 4 Comparison of the target value and the actual value of the PV array maximum power point under dynamic partially shaded conditions

\begin{tabular}{|c|c|c|c|c|}
\hline PV Array & \multicolumn{4}{|c|}{ PV partially shaded area \% } \\
\hline Single cell shaded area & $20 \%$ & $40 \%$ & $60 \%$ & $80 \%$ \\
\hline PV output target power & $40.00 \mathrm{~W}$ & $37.20 \mathrm{~W}$ & $35.60 \mathrm{~W}$ & $34.40 \mathrm{~W}$ \\
\hline PV output actual power & $39.69 \mathrm{~W}$ & $36.98 \mathrm{~W}$ & $35.36 \mathrm{~W}$ & $34.20 \mathrm{~W}$ \\
\hline
\end{tabular}

\section{References}

[1] Maganioti, A.E., Chrissanthi, H.D., Charalabos, P.C., Andreas, R.D., George, P.N. and Christos, C.N. (2010) Cointegration of Event-Related Potential (ERP) Signals in Experiments with Different Electromagnetic Field (EMF) Conditions. Health, 2, 400-406.

[2] Bootorabi, F., Haapasalo, J., Smith, E., Haapasalo, H. and Parkkila, S. (2011) Carbonic Anhydrase VII-A Potential Prognostic Marker in Gliomas. Health, 3, 6-12.

[1] Benner, J. P. (1999) Photovoltaics. IEEE Spectrum.

[2] Carlson, D.E. (1995) Recent Advances in Photovoltaics. Proceedings of the Intersociety Engineering Conference on Energy Conversion.

[3] IEA. (2003) Photovoltaic Power Systems Programme. http://www.iea-pvps.org/.

[4] Ji, Y.H., Jung, D.Y., Kim, J.G., Kim, J.H., Lee, T.W., and Won, C.Y. (2011) A Real Maximum Power Point Tracking Method for Mismatching Compensation in PV Array Under Partially Shaded Conditions. IEEE Transactions on Power Electronics, 26.

[5] KYOCERA-Solar. http://www.kyocerasolar.com/commercial-solutions/solar-panels/currentproducts.htm

[6] Tseng, C.W. (2005) Analysis and Research of Impedance Matching Theory for The Maximum Power Point Tracking of Solar Power System. Department of Electrical Engineering, Chung Yuan Christian University.

[7] Cheng, Y.H.. (2009) Design and implementation of renewable power generation system. Department of Electrical Engineering, NUU.

[8] Huang, S.H. (2012) A MPPT method for Stand-alone PV System: Three-point-weighting method with One-middle-point-Tracking Comparison Method. Monthly Journal of Taipower's Engineering, 94-104. 